Gut, 1989, 30, 299-304

Alimentary tract and pancreas

\title{
Late results of a prospective randomised study comparing forceful dilatation and oesophagomyotomy in patients with achalasia
}

\author{
A CSENDES, I BRAGHETTO, A HENRÍQUEZ, AND C CORTÉS \\ From the Department of Surgery and Radiology, University of Chile, Santiago, Chile
}

SUMMARY Late results in 81 patients with achalasia treated in a prospective randomised study comparing forceful pneumatic dilatation with the Mosher bag and surgical anterior oesophagomyotomy by abdominal route, are reported. There were no deaths from either of the treatments. Two patients (5.6\%) had a perforation of the abdominal oesophagus after pneumatic dilatation and were excluded from late follow up. In patients having surgery at radiological evaluation there was gullet diameter significantly increased at the oesophagogastric junction and decreased at the middle third of the oesophagus. One patient was lost from follow up and one died of an oesophageal carcinoma, leaving $95 \%$ of excellent results at the late follow up (median 62 months). Resting gastro-oesophageal sphincter pressure decreased significantly to approximately $10 \mathrm{mmHg}$; this was maintained five years after surgery. By contrast, in patients having pneumatic dilatation, there were good results in only $65 \%$ (follow up median 58 months), with $30 \%$ failures. One patient was lost from follow up and one developed oesophageal carcinoma. Measurement of resting gastro-oesophageal sphincter pressure after dilatation was highly predictive of the outcome. The study shows that surgical treatment offers a better final clinical result than pneumatic dilatation with the Mosher bag.

The aim of treating patients with achalasia of the oesophagus is to obtain an adequate emptying of the gullet into the stomach, either by rupture or by surgical division of the circular muscle fibres of the distal oesophagus, where the hypertensive gastrooesophageal sphincter is located.' 2 This can be achieved either by forceful dilatation, or by surgical oesophagomyotomy. We have previously reported the results of a prospective randomised study comparing the two treatments in 38 patients with achalasia.

The aim of this study is to report the late results of a greater number of patients included in this trial.

Address for correspondence: Attila Csendes MD. Department of Surgery. Hospital J J Aguirre. Santos Dumont 999, Santiago. Chile.

Accepted for publication 14 October 1988.
Methods

\section{PATIENTS}

Eighty one patients with typical achalasia grade I, II, or III as shown by radiological and manometric studies were included in this prospective randomised trial. All underwent upper gastrointestinal endoscopy in order to exclude other diseases. Chagas' serological test was positive in only 11 cases $(13.5 \%)$, but none had cardiovascular or colonic complications of this disease. The clinical features of the patients are shown in Table 1.

Patients with sigmoid oesophagus or grade IV achalasia were excluded.

MANOMETRIC STUDIES

These were done with a three-lumen catheter (Arndorfer) constantly perfused by water at $0.25 \mathrm{ml} /$ 
Table 1 Clinical features of patients

\begin{tabular}{lll}
\hline & \multicolumn{2}{l}{ Treatment } \\
\cline { 2 - 3 } & Dilatation $n=39$ & Surgery $n=42$ \\
\hline Age () & $\overline{4} 40 \cdot 2$ & $42 \cdot 7$ \\
Sex & $($ range 16-73) & (range 15-80) \\
& 16 men & 20 men \\
Chagas-positive & 23 women & 22 women \\
Length of follow & $5(13 \%)$ & $6(14 \%)$ \\
up (months) & Median 58 & Median 62 \\
& (range 24-144) & (range 26-156) \\
\hline
\end{tabular}

min using a pneumohydraulic pump (Arndorfer), connected to pressure transducers (Statham P23 Dd), and to a Gilson Polygraph (m8 PM). Pressures were expressed in $\mathrm{mmHg}$, taking as zero reference the end expiratory fundic pressure. Two rapid and two slow pull throughs were used for sphincter pressures, making at least four measurements in each patient. Two hundred and forty two manometric measurements were carried out in the patients: 73 before and 169 after, treatment. Doctors doing the manometric readings after both treatments were unaware of which procedure the patient had had.

\section{RADIOLOGICAL STUDIES}

In all patients upper gastrointestinal investigation was undertaken before and late after treatment by the same radiologist, using a standard radiological procedure in every case. The radiologist did not know what treatment had been performed and only knew that patients had achalasia. A careful evaluation by two different observers (AC-CC) was performed of the two main variables: (a) maximal internal diameter $(\mathrm{mm})$ of the middle third of the thoracic oesophagus; (b) maximal diameter ( $\mathrm{mm}$ ) of the gastro-oesophageal junction. These observers were not aware of what treatment the particular patient had had.

\section{EN DOS COPY}

This was carried out in all patients before treatment and was repeated at a median of 47 months (range 26 to 70 ) in the 22 of the dilated and at a median time of 54 months (32 to 86) in 33 of the operated group. Doctors carrying out endoscopy were not aware of what procedure has been performed on the patient.

\section{ACID REFLUX TEST}

The standard acid reflux test was carried out by using a glass electrode (Radiometer, Copenhagen) attached to the middle orifice of pressure catheters. It was introduced to the stomach and fasting $\mathrm{pH}$ was recorded. The patients were in recumbent position. The $\mathrm{pH}$ glass electrode was always standardised with two different standard buffer solutions straight from the factory. After locating the lower oesophageal sphincter, the electrode was located $5 \mathrm{~cm}$ proximally and oesophageal $\mathrm{pH}$ was recorded for five minutes. If this $\mathrm{pH}$ was below 4 , it was registered as spontaneous reflux $(+++)$. If $\mathrm{pH}$ remained above 4 , it was introduced to the stomach and $300 \mathrm{ml} \mathrm{HCl} 0 \cdot 1$ IN was instilled into the stomach. The electrode was again positioned in the oesophagus for 10 minutes. If $\mathrm{pH}$ dropped below 4, it was recorded as induced reflux $(++)$. If $\mathrm{pH}$ still remained above 4 , three manoeuvres were carried out: Valsalva manoeuvre, elevating the legs and external abdominal compression of $50 \mathrm{mmHg}$. If $\mathrm{pH}$ dropped below 4 , it was recorded as provoked reflux $(+)$. If $\mathrm{pH}$ remained above 4 , the test was considered as negative or absence of reflux. The period of time for which $\mathrm{pH}$ had to be at less than four for the test to become positive was one minute.

\section{PNEUMATIC DILATATION}

This was done under fluoroscopy by the authors in all patients using a Mosher bag. ${ }^{34}$ Patients were hospitalised for 24 hours and premedicated with 0.5 $\mathrm{mg}$ atropine and light pharyngeal anaesthesia. With the bag in the correct position, it was inflated rapidly to $5.4 \mathrm{lbs} / \mathrm{in}^{2}$ for $10-20$ seconds: this procedure was repeated twice. The maximum diameter of the Mosher bag at the gastro-oesophageal junction when completely inflated was $4 \mathrm{~cm}$. The duration of this procedure was one minute. It was not possible for the bag to remain inflated for more than 20 seconds each time, because all patients experienced intense pain and discomfort. When the bag was removed, it always was marked with blood, indicating some degree of mucosal damage. An immediate $x$-ray examination was done in order to exclude a perforation. All patients were observed for 24 hours and then discharged.

\section{SURGICAL TECHNIQUE}

All patients underwent surgery through the abdominal route..$^{35}$ The phreno-oesophageal membrane was sectioned and the abdominal oesophagus was carefully dissected and tensioned. Anterior oesophagomyotomy was carried out to the left of the anterior vagus nerve, dividing $5-6 \mathrm{~cm}$ oesophageal muscle layers and 5-10 $\mathrm{mm}$ of gastric fibres. The mucosa was left intact, although it was accidentally opened in three patients. In all patients the greater curvature of the stomach was sutured by a running suture to the muscular borders of section (as in the Dor technique) with Vicryl 3-0, for the following reasons: (a) to avoid the appearance of fistula if the mucosa was opened; (b) to maintain separation of muscular borders, avoiding a recurrence of achalasia; 
(c) to create an antireflux mechanism. In 30 patients a muscle biopsy of the distal oesophagus was taken. Patients remained in hospital for five to six days after surgery. Feeding started 48 hours after surgery.

STATISTICAL ANALYSIS

Student's $t$ test was used for calculation of significant differences.

\section{FOLLOW UP}

A careful clinical follow up was undertaken every year after treatment. A standard questionnaire was used in each case, asking for presence of dysphagia, heartburn, loss or gain of weight, respiratory symptoms and whether the patient was happy or not with the result of his treatment. In this aspect, doctors doing this questionnaire were aware of what procedure has been performed in each case. Radiological studies were done two months and five years after treatment. Manometric evaluation was done two months, one year, and five to seven years after treatment.

\section{RANDOMISATION}

No rejection or refusal of treatment was recorded and all patients gave their informed consent to be included in this trial begun in 1973 and ended in December 1984. After completion of all clinical and laboratory analysis, and if patients were suitable for either treatment, the treatment was randomly selected from an envelope containing 45 sheets marked 'dilatation' and 45 marked 'surgery'. Final evaluation ended in December 1986, having taken 14 years to complete. Only four patients were excluded because of severe cardiovascular or respiratory diseases that contraindicated surgery.

\section{Results}

No deaths occurred in the present series. Two $(5 \cdot 4 \%)$ dilated patients were perforated and underwent immediate surgery, but they are not included in the operated group. No significant morbidity was recorded after surgery, except one subphrenic abscess, which was drained. No postoperative fistulae were seen. Before treatment all patients had severe and long standing dysphagia. After treatment, dysphagia was absent in 18 cases of the dilated group $(49 \%)$ and in 33 patients $(79 \%)$ of the operated groups. It was severe in 10 cases $(27 \%)$ of the dilated and in one patient $(2 \%)$ of the operated groups $(\mathrm{p}<0 \cdot 01)$.

There was a significant decrease in the diameter of the middle third of the oesophagus and a significant increase in the diameter of the oesophagogastric junction after treatment $(p<0.0001)$; this increase
Table 2 Radiological studies

\begin{tabular}{lll}
\hline & \multicolumn{2}{l}{ Treatment } \\
\cline { 2 - 3 } Diameter $(\mathrm{mm})$ & Dilatation & Surgery \\
\hline Gastroesophageal junction & & \\
Before treatment & $2 \cdot 69(1 \cdot 4)$ & $2 \cdot 82(1 \cdot 3)$ \\
Late follow up & $7 \cdot 2(2 \cdot 4)^{*}$ & $9 \cdot 0(1 \cdot 6)^{*}$ \\
Median & 58 & 62 \\
Range & $24-144$ & $26-156$ \\
$\begin{array}{l}\text { Middle third of the oesophagus } \\
\text { Before treatment }\end{array}$ & $41 \cdot 77(70)$ & $51 \cdot 97(8 \cdot 8)$ \\
Late follow up & $28 \cdot 77(6 \cdot 1)^{*}$ & $26 \cdot 30(4 \cdot 6)^{*}$ \\
\hline
\end{tabular}

${ }^{*} \mathrm{p}<0 \cdot 0001$.

was greater in the operated, than in the dilated group $(\mathrm{p}<0.01)$ (Table 2).

Endoscopic evaluation four to seven years after surgery in 55 patients showed that $70 \%$ of the whole group had a normal oesophageal mucosa with no evidence of macroscopic oesophagitis in any patient, with an empty oesophagus and easy passage of the endoscope to the stomach. The results of gastrooesophageal sphincter pressure measurements are shown in Tables 3 and 4.

There was a significant decrease in the resting gastro-oesophageal sphincter pressure after both treatments $(p<0 \cdot 001)$, but this decrease was greater in the operated group $(p<0 \cdot 01)$. The behaviour of the sphincter was different in the two groups. In the dilated patients three distinct patterns were recorded among the 32 patients in whom it was possible to do manometric studies. Patients who were well and asymptomatic at late follow up had significantly decreased sphincter resting pressures (median

Table 3 Resting lower oesophageal sphincter pressures. Effect of forceful pneumatic dilatation

n Mean pressure $(\mathrm{mmHg})$

Group I

Well at late follow up before treatment $20 \quad 32 \cdot 15(13 \cdot 5)$

2 Months post dilatation

$2016 \cdot 4(7 \cdot 1)^{*}$

5 Years post dilatation median 54

(26-144)

9 15.6(3.0)*

Group II

Needed repeated dilatation before treatment

2 Months after first dilatation

2 Months after second dilatation

Group III

Needed surgery before treatment

2 Months after first dilatation

$636 \cdot 5(12 \cdot 7)$

$6 \quad 21 \cdot 7(7 \cdot 2)^{*}$

$620 \cdot 3(9 \cdot 5)$

$6 \quad 32 \cdot 83(15 \cdot 8)$

$626 \cdot 33(9 \cdot 5)$ 
Table 4 Resting lower oesophageal sphincter pressure. Effect of oesophagomyotomy

\begin{tabular}{llc}
\hline & $n$ & Mean pressure $(\mathrm{mmHg})$ \\
\hline Before treatment (a) & 33 & $37 \cdot 94(18 \cdot 1)$ \\
2 Months after surgery (b) & 33 & $9 \cdot 82(10 \cdot 1)$ \\
5 Years after surgery (c) & 24 & $10 \cdot 13(5 \cdot 37)$ \\
(median 58 months, range 39-156) & & \\
\hline
\end{tabular}

a $v$ b p $<0.0001: a v c p<0 \cdot 0001 ; \mathrm{b} v \mathrm{c}$ ns.

54 months with range 26 to 149 months), which remained at a similar level five years after treatment. In patients who needed further dilatation, this decrease in resting pressure was less, although significant compared with values before treatment. After redilatation, resting sphincter pressure remained at a similar level to the previous values after first dilatation. In the patients who needed surgery, the decrease in resting sphincter pressure was not significant compared with pressure before treatment. Sphincter pressures after dilatation correlated closely with clinical results and were predictive of the late outcome of the procedure.

In contrast, in 33 of 42 patients after surgery in whom it was possible to perform manometric studies, sphincter pressure decreased to a mean of $10 \mathrm{mmHg}$, and remained constant late after surgery, at a median 58 months with range from 39 to 156 months (Table 4). None of these patients had absent sphincter pressures. The resting intraoesophageal pressure decreased to negative values after treatment (Table 5). No significant changes were seen in the amplitude of the oesophageal waves after dilatation $(\mathrm{p}>0.5)$, but after surgery there was a significant increase in amplitude $(\mathrm{p}<0 \cdot 0005)$ (Table 5). After surgery some peristaltic waves were recorded as also seen in some patients after dilatation. The results of the acid reflux

Table 5 Manometric features of the body of the oesophagus

\begin{tabular}{|c|c|c|}
\hline & Dilatation & Surgery \\
\hline \multicolumn{3}{|c|}{1 Amplitude of oesophageal pressure waves $(\mathrm{mmHg})$} \\
\hline Before treatment & $22 \cdot 56(18 \cdot 8)$ & $22 \cdot 74(15 \cdot 6)$ \\
\hline${ }^{*}$ Late follow up & $18 \cdot 72(13 \cdot 9)$ & $34 \cdot 74(20 \cdot 1)^{*}$ \\
\hline Median & 54 & 58 \\
\hline Range & $26-144$ & $39-156$ \\
\hline \multicolumn{3}{|c|}{2 Simultaneous waves } \\
\hline Before treatment & $98 \%$ & $98 \%$ \\
\hline Late follow up & $87 \%$ & $72 \%$ \\
\hline \multicolumn{3}{|c|}{3 Intraoesophageal resting pressure $(\mathrm{mmHg})$} \\
\hline Before treatment & $+5 \cdot 7$ & $+6 \cdot 0$ \\
\hline${ }^{*}$ Late follow up & $-1 \cdot 2$ & $-4 \cdot 2$ \\
\hline
\end{tabular}

Table 6 Reflux acid test after treatment

\begin{tabular}{lcl}
\hline Acid reflux test & After dilatation $n=37$ & Surgery $n=42$ \\
\hline$(+++)$ or $(++)$ & $8 \%$ & $28 \%$ \\
$(+)$ or $(-)$ & $92 \%$ & $72 \%$ \\
\hline
\end{tabular}

test are in Table 6, which shows that after dilatation three patients $(8 \%)$ had a positive test. After surgery, 12 patients $(28 \%)$, however, $28 \%$ had a positive reflux test but only two of those 12 had mild heartburn. In the final assessment the assessor knew which patient had which treatment. All cases were examined clinically by the authors and no case sent only a filled questionnaire without coming to medical examination. The assessment were done according to a standard questionnaire that was defined at the beginning of this trial.

The final clinical results are shown in Table 7 . After dilatation 37 patients were studied, excluding the two with perforation and immediate surgery. In the dilated group 20 were asymptomatic that is, had gained weight and had only occasional dysphagia when eating a solid meal, or had some emotional stress of different nature. Four were submitted to a second dilatation, with good results at late follow up, with a median time of 58 months (range 24 to 144). This gives 24 patients $(65 \%)$ with good results after dilatation. There were $11(30 \%)$ with poor results who had to have surgery (eight patients), or had bad results after dilatation (two patients), or recurred, but refused treatment (one patient). One patient was lost to follow up and one developed an oesophageal carcinoma at the upper third of the oesophagus eight years after dilatation.

In contrast, among the 42 patients treated with surgery, one died six months later from an unrelated disease and was considered lost from follow up. Forty $(95 \%)$ were asymptomatic at late follow up with a median of 62 months (range 26-156) and were satisfied with their treatment. One patient developed

Table 7 Final late results

\begin{tabular}{lll}
\hline & After dilatation $n=37$ & Surgery $n=42$ \\
\hline $\begin{array}{l}\text { Length follow up } \\
\text { Median }\end{array}$ & 58 & 62 \\
$\quad$ Range & $24-144$ & $26-156$ \\
Well & $20(54 \%)$ & $40(95 \%)$ \\
Redilated and asymptomatic & $4(11 \%)$ & - \\
Redilated but persistence of & $2(5 \%)$ & - \\
$\quad$ dysphagia & & - \\
Needed surgery & $8(22 \%)$ & - \\
Recurrence not treated & $1(2 \cdot 7 \%)$ & $1(2 \cdot 5 \%)$ \\
Oesophageal carcinoma & $1(2 \cdot 7 \%)$ & $1(2 \cdot 5 \%)$ \\
Lost from follow up & $1(2 \cdot 7 \%)$ & \\
\hline
\end{tabular}


an oesophageal carcinoma in the middle third of the oesophagus nine years after surgery. The result after operation was significantly better than after dilatation $(\mathrm{p}<0 \cdot 01)$.

\section{Discussion}

The value and risks of forceful dilatation compared with surgical oesophagomyotomy in the treatment of achalasia are unclear." The results of the present prospective study suggest that surgical treatment offers better longterm success compared with pneumatic dilatation with the Mosher bag. This study is at present the only prospective randomised trial comparing the two treatments.

There are some retrospective analyses comparing forceful dilatation and oesophagomyotomy in patients with achalasia. In a large retrospective study from the Mayo Clinic, ${ }^{7}$ comparing 431 patients treated with dilatation with 468 patients after oesophagomyotomy, excellent or good results were reported in $65 \%$ of the dilated and in $85 \%$ of the operated patients $(\mathrm{p}<0 \cdot 001)$. There were two deaths after dilatation and one after surgery. Avranitakis ${ }^{x}$ reported good results in $65 \%$ of dilated patients and in $91 \%$ after oesophagomyotomy, while Yon and Christensen" found $46 \%$ and $85 \%$ of good results respectively, very similar to our findings. All these results are retrospective studies comparing patients with different criteria.

Vantrappen ${ }^{6}$ 1" $u$ uses progressive dilatation until the criteria for effective treatment are met: he reported excellent to good results in $77 \%$. Similar data were also published by Fellows et al, " using pneumatic dilatation under general anaesthesia. Lishana and Dellipiani'2 had $89 \%$ good results in 18 patients forcefully dilated with the Brown McHardy dilator. It is true that the results of the present study are relevant only when the Mosher dilator is used, but we believe that it would be almost impossible to design a prospective randomised study comparing each type of dilator to surgery, or one dilator with another. We accept, however, that in the hands of other experts, the pneumatic dilator may give good results. One previous criticism of our technique was the duration of our dilatation: that is why in later patients dilatation time was prolonged from 10 to 20 seconds, but similar results were obtained when using only five seconds."

The number of patients entering this trial was increased from 38 to 81 in order to strengthen the power of the trial. This increase in numbers, however, did not change the results. The follow up has been longer than in many previous reports. Another criticism of our previous report was that only patients with mild, or moderate dilatation of the oesophagus were included. "In the present study, however, the percentage of patients with mild (less than $4 \mathrm{~cm}$ ), moderate $(4-7 \mathrm{~cm})$, and severe (more than $7 \mathrm{~cm}$ ) grade of dilatation was 35,45 , and $20 \%$ respectively.

Advantages of forceful dilatation are that it is a short procedure, where the outcome can be assessed immediately with patients discharged from hospital after 24 hours; second, it avoids surgery. It also has several disadvantages: the incidence of perforation varies from 1 to $6 \% ;^{3 \dagger}$ it is painful and the rupture of circular muscle fibres is uncontrolled. If a patient has to have surgery later, the fibrous tissue in the distal oesophagus makes surgical dissection more difficult. In these circumstances the mucosa may have to be opened.

Several groups have reported better results after surgery. ${ }^{1 .-16}$ The advantages of surgery are: the division of circular muscle fibres is done under direct vision and is complete. Second, if there is another abdominal disease, it can be treated immediately. There are also several disadvantages: there is always some risk, but this is very low and mortality seems to be similar in both treatments; several days of hospitalisation are needed and complications can occur; the incidence of reflux if greater after surgery, varying from 5 to $50 \% .^{1.3-1 h}$ In this study the $\mathrm{pH}$ test was positive after surgery in $28 \%$, but the incidence of heartburn was very low. Standard acid reflux test used here is a simple method, and reflux has been measured only in very few studies objectively after treatment. This study is the largest analysis of this aspect. With good surgical technique reflux can be avoided. Incision of the oesophagus must be between 5-6 cm long, in order to ensure complete division of the hypertensive sphincter. The incision must not extend more than 5-10 $\mathrm{mm}$ into the stomach, because longer incisions can produce a high incidence of reflux. ${ }^{17}$ We believe that the gastric sling fibres have little or no role in the obstructive mechanism in achalasia, but an intact band at the gastrooesophageal junction can lead to a constriction and herniation of the mucosa. Addition of an antireflux procedure such as the Dor technique, which is an anterior Hemi Nissen operation, produces a beneficial effect. No patients operated on in this study had complete abolition of sphincter pressure, with values that remained around $10 \mathrm{~mm}$ at late follow up. Some return of peristaltic waves after surgery or dilatation was recorded, but explanation of this is not clear. An important conclusion from the present observations is that treatment in achalasia should aim at decreasing lower ocsophageal sphincter pressure to approximately $10 \mathrm{mmHg}$. This is achieved by surgery and should also be the aim of pneumatic dilatation. The technique of dilatation used here, however, had no effect on lower 
oesophageal sphincter pressure in six patients and in another six the effect was quite modest.

The clinical analysis, the radiological demonstration of the diameter of the thoracic oesophagus, the increase of the diameter at the gastro-oesophageal junction, and the observation of the radiologist during fluoroscopy suggest better oesophageal emptying. Endoscopical analysis in $70 \%$ of the cases showed an empty oesophagus with no evidence of macroscopic oesophagitis; which is another index of good emptying.

It is also clear that when treatments are compared, expertise and experience play an important role in their evaluation. Every author has a special method for dilatation and surgical procedures differ between surgeons. The result of this prospective randomised trial in patients with achalasia of the oesophagus show that surgical treatment offers better results than forceful dilatation with the Mosher bag.

\section{References}

1 Heitman P, Espinoza J, Csendes A. Physiology of the distal csophagus in achalasia. Scand $J$ Gastroenterol 1969; 4: 1-11.

2 Uribe P, Csendes A, Larraín A, Ayala M. Motility studies in fifty patients with achalasia of the esophagus. Am J Gastroenterol 1974; 62: 333-6.

3 Csendes A, Velasco N, Braghetto I, Henríquez A. Prospective randomized study comparing forceful dilatation and esophagomyotomy in patients with achalasia of the esophagus. Gastroenterology 1981; 80: 789-95.

4 Csendes A, Strauzer T. Long-term clinical, radiological and manometric follow-up period of patients with achalasia treated with pneumatic dilatation. Digestion 1974; 11: 128-34.

5 Csendes A, Larraín A. Strauzer T, Ayala M. Long-term clinical, radiological and manometric follow-up period of paticnts with achalasia of the esophagus treated with esophagomyotomy. Digestion 1975; 13: 141-5.

6 Vantrappen G, Janssens J. To dilate or to operate? That is the question. Gut 1983; 24: 1013-9.

7 Payne NS, King RM. Treatment of achalasia of the esophagus. Surg Clin N Am 1983; 63: 963-70.

8 Avranitakis C. Achalasia of the esophagus: a reappraisal of esophagomyotomy vs forceful pneumatic dilatation. Dig Dis 1975; 20: 841-6.

9 Yon Y, Christensen J. An uncontrolled comparison of treatment for achalasia. Ann Surg 1975; 182: 672-6.

10 Vantrappen G, Hellemans J, Deloof W, et al. Treatment of achalasia with pneumatic dilatation. Gut 1971; 12: 268-75.

11 Fellows IW, Ogilvie AL, Atkinson M. Pneumatic dilatation in achalasia. Gut $1983 ; 24: 1020-3$.

12 Lishman AH, Dellipiani AW. Management of achalasia of the cardia by forced pneumatic dilatation. Gut 1982; 23: $541-4$.

13 Ellis FM, Crozier RE, Watkins E. Operation for esophageal achalasia. J Thorac Cardiovasc Surg 1984; 88: $344-51$.

14 Mandelstam P, Block C, Newel L, Dielon M. The role of bougienage in the management of achalasia - the need for reappraisal. Gastrointest Endosc 1982; 3: 169-72.

15 Castrini G, Pappalardo G, Mobarhan S. New approach to esophagocardiomyotomy. J Thorac Cardiovasc Surg 1982; 84: 575-8.

16 Duranceau A, La Fontaine ER, Vellieres B. Effects of total fundoplication on junction of the esophagus after myotomy for achalasia. Am J Surg 1982; 143: 22-8.

17 Ellis FH, Kisen JC, Schlegel JF. Esophagomyotomy for achalasia of the esophagus. Ann Surg 1967; 166: 640-56. 